\title{
13 \\ ALTERNATIVE ROUTES TO LABOR FLEXIBILITY
}

\author{
Guy Standing
}

\section{INTRODUCTION}

Regular wage labor is neither the present nor the future for a growing proportion of the population of industrialized countries. Almost perversely, this realization has coincided with a loss of a radical, progressive vision of the Good Society. Instead, the fear is that we are witnessing the creation of a disjointed society made up, in Marx's words (describing preproletarian workers), "by simple addition of homologous magnitudes, such as potatoes in a sack form a sack of potatoes." In the past decade or so, we have seen the limit of Gramsci's brilliant insight, Fordism, which no longer seems the predominant form of the labor process (if it ever was). However, most of us are still searching for an alternative paradigm of the present and an alternative avenue to utopia. Without some vision, however modest, we might as well stay in our gardens or backyards. And perhaps that is a clue, for access to a garden is not just a residue of Thomas More's Utopia, but a part of many modern visions, encapsulating the possibility of combining different forms of paid and own account work. In the reality of Europe today, we live in disturbing times, when inequalities are worsening and when the Galbraithian strictures on American society of the 1960s are being writ large in European cities such as Rome, London, and Amsterdam, with extraordinary private affluence (of a few) coexisting with public squalor (of many). That is one context in which to approach the issue of alternative paths for the 1990s.

Another contextual point can be derived from the prevailing vocabulary. The "key words" of an era both define the underlying trends and help in identifying the emerging opportunities for better alternatives. Among the key words of the 1980s were individualism, privatization, flexibility, deregulation, structural adjustment, liberalization, and supply-sideism. ${ }^{1}$ As we know, those key words are all part of the ideology that has played all the best tunes of the past decade. It is an era in which the main voices have been profoundly anticorporatist, antisocialist, and antisocial. Margaret Thatcher's famous quip was no slip of the tongue:

There is no such thing as society. There are individual men and women, and there are families.

It is this rejection of collective responsibility and sense of community and social solidarity, as well as the very active promotion of self-interest, which epitomizes the mainstream of the past decade, even though "Thatcherism" represents its extreme variant. 
This chapter is an attempt to reflect on two routes that different societies might follow to varying degrees in the 1990s. These are built on stylized facts about labor process developments, the analysis of which has been pioneered by many of those who attended the "Pathways to Industrial and Regional Development in the 1990s" conference in Los Angeles in 1990, and on our ongoing country studies of labor flexibility in the ILO. Space precludes empirical and documentary support for the stylized facts, although they are fairly well known. Moreover, of course, juxtaposing opposing scenarios does injustice to the nuances of any particular country or labor process. It will be taken as axiomatic that the changes in the labor process (the structure of employment, the forms of labor status, types of contract, forms of payment, etc.) reflect changes in the structure of production, including technological and organizational dimensions.

The stylized facts that we need to keep in mind include the extensive erosion of secure full-time employment, the persistence of mass unemployment and "underemployment" of one form or another, the crumbling of unionized mass production manufacturing, the growth of both "functional" and external labor flexibility, the widening of wage and earnings differentials, and the failure of traditional social security systems (both Beveridge and Bismarck varieties) either to compensate for the labor process fragmentation or to provide the income security anticipated in the social consensus societies of the post-1945 era. Although all these have been mainstream trends that each avoided to some extent somewhere or other, even the most corporatist societies, of the Nordic region principally, have failed to arrest most of them.

Ultimately, the greatest failure of the 1980s was the disturbingly under-played tune about distribution. One has difficulty thinking of some haven where income, wealth, and other socioeconomic distribution improved; one has no difficulty whatsoever in naming a long list of countries where they worsened, despite the disgraceful shortage of data needed to make comprehensive pictures.

It might be useful to contemplate two possible scenarios that start from recent trends. The first will be called subordinated flexibility, representing a continuation of the dominant trends of the 1980s; the second will be called cooperative flexibility, although one might call it integrative or social flexibility, in that it represents the vital positive value of labor security and collective regulations. The hope is that we can move on from those key words cited at the outset, and thereby point to a more attractive set of options than implied by the dominant trends in most of Western Europe and North America.

\section{SOME CONCEPTUAL PRELIMINARIES}

In a series of papers over the past few years, it has been argued that since the 1970s the postwar social consensus has been disrupted by the erosion of seven forms of labor security or "labor rights," each of which was strengthened in the preceding thirty years or so (Standing 1983, 1989). Those are:

1 income security;

2 labor market security;

3 employment security;

4 work security; 
5 job, or occupational, security;

6 labor process security; and

7 labor reproduction security.

These are defined elsewhere, but it is strategically important to distinguish between what have been called meta rights and instrumental rights. The former are those that are longterm goals reflecting fundamental values, the attainment of which is not realistic in the short term but which should be pursued steadily and consistently; instrumental rights are those that are necessary or helpful in the pursuit of real human values and aspirations. All social and economic policies should be judged by whether or not they enhance the prospect of attaining meta rights. Many critics of the supply-side orthodoxy of the 1980s have erred by mixing up the two types of labor rights, often giving precedence to the defense of labor market security (i.e. the pursuit of "full employment") and to anguished concern over employment security, both of which should be treated as instrumental rather than meta rights. An alternative strategy to the current orthodoxy should be based on the recognition that the labor meta rights are income security and labor process security. One way of interpreting the trends of the dominant orthodoxy of the 1970s and 1980s is that what would be meta rights in social democratic visions of a Good Society were treated as instrumental or secondary rights, or even rejected as rights altogether.

In this chapter it will be taken as axiomatic that the meta rights of a Good Society would include the following:

1 generalized income security for all, consistent with the economic level of development; 2 declining inequality, not the reverse;

3 labor process security, involving the strengthening of a sense of community, solidarity and active participation, through economic democracy; and 4 the right to occupation, and the right to work.

These are stated baldly, in the sense that Gunnar Myrdal used to urge social scientists to state their values at the outset, and also because they may help give a structure to the consideration of key elements of the alternative scenarios this chapter attempts to highlight. In that context, it might be useful to reiterate some crucial conceptual distinctions that are fundamental to the flexibility debate.

Labor process security is taken to mean that workers and particularly their representative organizations have the capacity to determine, or the possibility of influencing, the development of the labor process, defined in terms of working conditions, work structures, skill acquisition and reformulation, and so on. If, for instance, management has almost full control over labor relations, and the workers little or none, then there is definitionally labor process insecurity. One could never attain "full" labor process security, in part because one would find it very hard to agree on any ideal structure of institutional mechanisms. Nevertheless, labor process security is a meta right, a question of degree and of trends, in the sense that reforms and changes in labor practices should be judged by whether they increase or diminish the existing degree of labor process insecurity.

Another distinction that must be preserved is between job and employment security. Too many authors refer to job security when what they mean is employment security. The 
former exists if workers have secure niches within an enterprise or within the labor process more generally, niches consisting of a protected bundle of tasks that cannot be abrogated arbitrarily. By contrast, employment security exists if workers have protection against arbitrary dismissal from employment. In the 1980s many groups lost both forms of security, some lost only one, and some conceded on one to gain on the other.

One must also distinguish between an occupation and a job. This is critically important for the subject matter of our deliberations. It is significant that in the English language, the etymologically earliest definition of occupation was taking possession of a piece of territory. An occupation involves a career of learning and the mastery, or possession, of the mysteries of a craft or profession. There is a sense of continuity, a progression, and above all an acquisition of status, control, and autonomy. The status aspect of occupations is pervasive. One still occasionally thinks of an occupation as a "calling." The term stems from a social structure in which the detailed or technical division of labor was relatively undeveloped, when apprentices were introduced to the "mystery" of a craft. In intention, the concept of occupation refers to a positive idea of work, as creative activity, the combination of intellectual and manual activities-conception and execution - in the context of "skill" refinement. One is tempted to believe that for many workers in the latter part of the twentieth century the development of the technical and social divisions of labor, under the guise of "numerical" and "functional" labor flexibility, has debased the notion of occupation.

By contrast, a "job" is a much humbler word, conveying an activity, a limited and limiting piece of work, a narrow set of tasks. Often it has a pejorative meaning attached to it, implying a lack of permanency, a lack of accumulated wisdom or "skill" and an aura of insecurity. Usually it conveys a task or period of employment of short and limited duration. Thus "job work" is another term for "piece work." A job is what one does now, an occupation is what one is. One would not say of a job what John Ruskin said of an occupation:

The character of men depends more on their occupation than on any teaching we can give them.

If someone has a job, without occupation, the social psychologists might be able to tell us the likely behavioral consequences. Those surely cannot be favorable in influencing the development of community and social solidarity. But by putting labor market and employment security on a pedestal, the tendency to idealize "jobs" becomes overwhelming.

It is scarcely less relevant to our task to reflect on another much-used key word-skill. A striking theme of the era is that everywhere politicians, economists, employers, unions, the media, and sundry consultants are agreed on one point; that training is vital and that raising skill levels is the principal means of solving "Eurosclerosis," cutting unemployment, combatting labor market fragmentation, and solving diverse other economic and social ills. To dissent is to risk excommunication from rational society. Training is the answer. If that does not work, then more training is the answer. If the unemployed do not perceive their need, they must be obliged to fulfill their duty to be trained. Already, in some countries being in labor market training schemes is equivalent 
to being employed, and the payment for the one is sometimes linked to payment for the other. ${ }^{2}$

It is in that context that we need to review our ideas about "skill," which has been a much-used term in the literature on labor flexibility. This, like the notion of a job, is also mixed up with ideas about occupation. In the abstract, a skill implies some combination of creative and manual abilities, a learning process and relevant work experience. To develop a skill usually requires training, but not always. More than ever, we need to distinguish very clearly between "vocational (occupational) training" and "job training," and between those and "orientation training." Frederic Taylor knew the differences very well, and the distinctions are even more relevant now. When training schemes are devised in terms of "minimal modules of employable skill," then not only has occupational training been reduced to job training but that has been transformed into a form of labor market regulation and labor control, in which trainees have little chance of autonomy or status.

Skill has three underlying meanings. To many, it reflects objective characteristics of work activity. This is skill as technique. Following Georges Friedman, one might start by dividing "skilled workers" in this sense into "specialists" and the "specialized," whereby the latter merely receive general training, do routinized work and are excluded from the design and comprehension of the production process. By contrast, specialists have far more discretion over when and how to carry out their tasks. But depicting skill as technique is actually rather unsatisfactory. One can be skilled in having certain capacities, but in practical terms be in a job that is not skilled in the specialist/occupation sense of the term. As far as the current era of labor flexibility is concerned, the way the erosion of occupational security has proceeded has probably accelerated the displacement of specialist craftsmen by specialized workers. over more and more traditional occupational spheres. We will return to this theme in subsequent sections.

A second notion of skill is autonomy in the production process; this links the relevant work activity to aspects of labor control, and various authors have actually contended that the skilled are differentiated primarily by the degree to which they have an autonomous status. If workers have no freedom over the use and development of manual capacities then surely those capacities will be restricted and distorted, thus removing a vital ingredient for the pursuit of occupation. It is not clear that many of those calling for more training to achieve labor flexibility are calling for a more autonomous work force.

A third and related meaning of skill relates to social status. Some social scientists argue that some occupations are called skilled simply because of custom or because barriers to entry have preserved an artificial or arbitrary skill hierarchy, perhaps complemented by a ritual of training that bears little relation to the task complexity, the general knowledge, or the specific knowledge required. This aspect of skill is closely related to mechanisms by which labor market inequalities are intensified.

These three aspects of skill should be kept in mind in assessments of the flexibility debate and literature. ${ }^{3}$ Indeed, if one took an integrated approach to both the notions of occupation and skill one might conclude that, despite the rhetoric to the contrary, trends in connection with skill and training in the 1980s were conducive to occupational deskilling, just as state involvement in the labor process was spreading in many countries, not contracting, while there was growing labor market regulation, not deregulation. 
We have dealt at rather tedious length with these conceptual issues, though they do seem crucial. One of the difficulties is that the vocabulary of the era is so deceptively benign, so liberating in tone. Who could be against policies that "provide workers with jobs," "give training," and "raise skills"? One hopes it is permissible to be uncomfortable. Those slogans seem to be answers that beg some rather awkward questions.

\section{SUBORDINATED FLEXIBILITY: LEGACY OF THE 1980s}

An essential part of the supply-side, libertarian agenda of the 1980s was that individualistic labor regulations should displace collective protective regulations, the twin justification being the desire to promote individual property rights and the belief that decentralized, individualized labor relations would ensure that markets would "clear" and unemployment fall (or rise) to its natural rate, determined by frictional and structural characteristics of the labor market. Ideally, legalization of employment contracts would impose behavioral norms based on individualistic common law principles. The courts could be relied upon to rule against collective interventions by reference to freedom in the labor market. Unions could indulge in fanfare flagwaving negotiations once every two or three years, when collective contracts were up for renegotiation, but ideally, by the tenets of those who advocate this libertarian path, this would become atavistic to the point of being unnecessary or ritualistic. To the extent that industrial or craft unions persisted they would be constrained to the point of being agents of management as much as agents of redistribution in favor of labor, let alone anything more radical.

Much of this agenda has been realized, to some extent. The individualization of employment contracts has extended way down the pay and occupational status scales and such contracts seem to have become more comprehensive as their practice has spread. While this trend is well advanced internationally, there has also been a steady erosion of collective and protective regulations. Implicit deregulation has been occurring by:

a) nonimplementation of protective regulations;

b) inadequate resources and personnel devoted to the task of policing existing regulations;

c) erosion of the capacity to resist among those denied their rights to protection;

d) a growing and cultivated sense of ambiguity among potential beneficiaries about the validity of such rights; and

e) an increasing loss of entitlements to protection by virtue of their labor status.

One major cause of the last form of implicit deregulation has been the widespread drift away from regular full-time employment in large enterprises. Major causes of the third and fourth forms have been deunionization (or more likely nonunionization), the persistence of chronically high unemployment, and the fears engendered by pervasive marginalization and widening inequality. Yet the biggest single factor in the implicit deregulation of the 1980s, compared with the implicit regulation of the 1960s and 1970s, was less tangible: fear changed sides. Whereas in the 1960s employers led in introducing practices ahead of regulations to avoid the threat of disruption, in the 1980s they led "deregulation" in the confident belief that the door was open, that others were going 
through it and that resistance was enfeebled.

Explicit deregulation has come about from the repeal of protective laws, whether wholly or, more commonly, by the creation of selective or "targeted" rather than general "rights," including the creation of loopholes in the legislative framework. Rights per se have been eroded by the tightening of conditionality, the necessary conditions for protection being made more restrictive and the onus of proof of right often being shifted to the workers and made more costly to pursue. Examples of explicit deregulation include the emaciation of the Wages Councils and the abolition of restrictions on night work for teenagers in the United Kingdom and legislation in the Federal Republic of Germany permitting unions and employers to derogate from working time legislation. There are numerous other cases all over Europe testifying to the underlying trend.

Although there has been both implicit and explicit erosion of protective mechanisms and collective institutions, it would be misleading to characterize this as pure deregulation. Proindividualistic regulations have been displacing procollective regulations. For proponents of what we should call a path to snbordinated flexibility, the 1980s might be seen as a transitional era, between one based on collective regulation to one of "contractualization." In the process, it is scarcely an exaggeration to say that those who could help themselves have been helped, whereas those who need help have been left to help themselves. It is also somewhat ironic that the current orthodoxy espouses "deregulation" by reference to the desire to create "full" employment. Whereas the old orthodoxy was that regulations were to protect workers in employment, the current one is that regulations should be judged by whether or not they enable more people to obtain jobs. Inter alia, this is one indication of the dubious primacy given to the notion of full employment. If critics of the prevailing orthodoxy continue to put full employment on the highest pedestal of social policy, they should not bellyache if regulations are adapted to promote that goal. 4

The causes of the growth of various forms of labor and employment flexibility will not be discussed here. But whether or not "the big firms are coming out of the corner," as Maryellen Kelly and Ben Harrison (1989) suggest (with good reason, in my view), the way labor and employment relations have been moving is unlikely to be reversed. ${ }^{5}$ The shift away from protected, full-time wage employment to more decentralized, less secure forms of labor relation, including outsourcing, subcontracting, and casualization, owes more to managerial, cost, and technological considerations than to a passing period of recession and structural adjustment. This means that conventional forms of protective regulation will be increasingly avoided, rather than evaded.

Four outcomes of this flexibilization deserve to be stressed-labor force fragmentation, the erosion and restructuring of economic entitlements (including welfare), the increasing need to combat the social and economic exclusion of a minority, and the continuing search for new means of raising productivity, given the partial demise or deficiencies of Taylorist methods in the more flexible labor process in the 1980s and anticipated for the 1990s.

\section{Labor force fragmentation}

The underresearched theme of labor process fragmentation is closely associated with 
growing inequality. ${ }^{6}$ We know that wage flexibility has grown and that this has been a euphemism for the ability of firms to lower real wages and widen or change wage differentials more easily. For instance, a survey of employers by the United Kingdom's Confederation of British Industry in May 1989 found that in the previous three years those firms reporting that it was easy to increase wage differentials had risen from a third to over a half, while those reporting that it was hard to do so had fallen from a third to a little over a quarter (CBI 1989:14).

Besides evidence on wage differentials, there are good reasons for believing that inequality has grown much more than conventional income and earnings data suggest. One reason is the "postcapitalist" nature of many employment relationships, and the ongoing process of labor-force fragmentation. Any conceptualization of that will be questionable, but it is surely essential to have an approximate image of the diverse strata to which new regulatory frameworks would have to apply. After all, one of the fundamental tenets of the postwar social consensus welfare state was the presumption that the labor force was unfragmented, with a norm of a male full-time wage worker in regular employment. In the 1990s, labor regulation and distribution policy will have to take account of something like the following ideal type pattern of fragmentation that has been growing in the "post-Fordist" era. ${ }^{7}$

In the context of more flexible labor processes, one can identify seven strata that deviate from the presumed norm of regular, full-time wage and salaried employment. At the top of the heap is an elite who have become "capitalist employees," through profit sharing, the acquisition of subsidized shares, and also by virtue of a growing range of fringe benefits, some of which have a full value way in excess of any taxable monetized value. Thus executives increasingly rely on "performance related" bonuses; in 1989 those accounted for 20 percent of management salaries in Britain, beyond which there were numerous other perks which have been growing in significance relative to other income sources (CBI 1989:5). In the USA, senior executives commonly receive over half their total income in non-salary forms. This elite have income security, work security, labor market security, employment security, job security, and labor process security, to the extent that they want it. The image one has of this elite is one of internationalization and increasing detachment from the labor process beneath them. In terms of inequality, much of their power lies in the concealed way their income and wealth accumulate, essentially legally. It is hardly comforting that perhaps the main drawback for those involved is that their lifestyle is generally intense and fraught with stress, which ultimately threatens any individual's hold on positions of status and control. At the very peak are a handful of rapacious individuals who seem to live on the margins of sanity, crazed by the pursuit of their $\mathrm{n}^{\text {th }}$ billion dollars, but below such Brechtian monsters are layers of very wealthy, sober groups affluently detached from national regulatory frameworks.

Below this elite category one can detect what might be called frenetic proficians. A notable phenomenon of the past decade has been the spectacular growth of nominally independent "consultants" and self-employed specialists. Key characteristics of this group are their relative youth, their frenetic work schedule and their self-satisfaction. Their expansion has been a feature of "flexible specialization." They have little labor security, but remind us of Tawney's tadpoles - most dying, but some becoming smug croaking frogs - except that a far larger proportion seem to thrive, because they have 
taken advantage of enterprise flexibility and the advantage to firms of using flexible specialists for short-term purposes. Whether the growth of this stratum will continue into the 1990s is hard to predict, since there may be a tendency for their "market price" to decline and for enterprises to find that as the cost of such workers come down it will be more advantageous to reintegrate those functions "in-house" to take account of economies of specialist knowledge. Yet it seems more likely that the external flexibility granted to the firm and the perceived autonomy granted to the proficians will combine to preserve semiautonomy. After all, these two aspects should create a monetized wedge that could be shared (each valuing the flexibility and autonomy that the more distanced working relationship entails).

A key aspect of the growth of these first two strata is that they tend to be beyond the welfare state and other regulatory institutions, increasingly having access to privatized benefits and neither contributing to nor gaining entitlement to social security benefits. This elitist detachment leads them to give political support to the associated transformation of the welfare state, from what Richard Titmus called the institutional redistributive model to the selective, residual model.

Those two strata represent the upper echelons of "popular capitalism." Below them are those who seem increasingly oriented to serving the interests of the upper strata, national bureaucrats, who retain the form of labor security obtained in the expansive times of the 1960s. In some countries this group may have lost some labor security, but it is hard to gain a clear picture of the seriousness of any erosion.

The fourth stratum down is hard to label, but might be called the capitalist worker stratum, consisting of those randomly fortunate wage-earning workers who, through share payments or access to successful profit-sharing schemes, accumulate savings that allow them to set up a full-time or part-time business or to live off dividends. The group may be only a tiny fraction numerically, but is ideologically rather important. They have gained in terms of income security and many have less need for employment or labor market security and so be less inclined to oppose implicit or explicit erosion of those forms of labor security.

Fifth down the labor process ladder is the old proletarian stratum, made up of unionized, mostly male workers in regular wage employment. This was the Beveridge and Bismarkian norm for the national insurance social security system. For well-known reasons, they have been declining numerically and have had their labor process security eroded in various ways. They have lost visibly and noisily, ironically often blamed and reviled by those who stood to benefit from their strength as much as by those who in short and narrow terms stood to gain from their defeat. Many of them have become a principal source of the growth of the bottom stratum outlined below. In general—despite the almost belated entrenchment of "insider-outsider" theory-there has been a tendency for this fifth stratum to lose in terms of income security, job security, work security, employment security, labor market security, and, most crucially, labor reproduction and labor process security. Part of the decline of their status, bargaining strength, and social cohesion comes from the erosion of job security (as distinct from employment security), stemming largely from a series of concessions to management on job demarcations. If wages are attached to job or task assignments and if workers are forced to concede the whole right to job retitling and rebundling to the will of management then effective wage 
flexibility can be boosted. Another striking feature of the regular CBI employer surveys in the United Kingdom is that in the past decade between a quarter and a third of all pay settlements have included concessions on working arrangements (CBI 1989:6, 13). This implies a reduction not only in job security but in income security.

This stratum has also lost employment security for similar reasons, and has been threatened by two-tier or multiple-tier employment contract structures and by two-tier wage structures, which may be transitional phenomena en route to flexible (not deregulated) employment. ${ }^{8}$ The fifth stratum has also been affected by the growth of working time flexibility. This might be seen as beneficial for both employers and workers, but unless flexible working is regulated by collective negotiation procedures, as is still the rule in Italy and the Federal Republic of Germany, it will be subordinated flexibility, essentially on the employer's terms, as in the case of increasing shift working and the abolition of restrictions on night work and weekend working. In short, one can hypothesize with some confidence that a growing proportion of such workers possess little more than a temporary niche, far more likely than ever before to move or be moved across "occupational" (sic) categories and industries. By that route they swell the sixth stratum.

That is what might best be called the flexiworker stratum, which has grown enormously in many countries in recent years, encompassing many "nonregular" forms of wage and other relatively low-income quasi-wage labor. The category is not so much deproletarianized as unproletarianized, having few if any of the laborist values of the traditional working class. For them the notion of the Rights of Labor would have few resonances beyond reminding them of fathers and mothers or their history books. They would not so much say farewell to the working class as refuse to acknowledge that they belong to it. The traditional vulnerability of such workers has been accentuated by the explicit and implicit "deregulation" of the time.

The category is particularly heterogeneous - so much so that one is tempted to subdivide it - but what the various groups have in common is an absence of any form of labor security, most of all labor process security. ${ }^{9}$ Whereas increasingly the fifth stratum has been expected to be functionally flexible (i.e. losing their crucial job security), flexiworkers are also labor-status flexible, likely to shift between wage and nonwage forms of employment, sometimes combining activities, sometimes not. Official labor force classifications are often hard to apply. Euphemisms are almost amusing. We have seen the emergence of "permanent temporaries," "self-employed employees," and "inhouse outworkers." Some firms maintain workers on temporary contracts for many years; some employment agencies put workers on permanent contracts as temporaries, guaranteeing them a retainer and employment status but not any particular job. The fragmentation can have grim effects that merely highlight the underlying insecurity. Recently there was a wretched legal case in the United Kingdom where fishermen who had been working for a firm for twenty years or more were deemed by the courts not to have satisfied the condition that to be entitled to redundancy benefits workers must have been in regular employment for at least two years. As their work in the period immediately preceding their redundancy had become irregular, the obligatory period of regular employment continuity had been broken. The fishermen had become flexiworkers without knowing it. 
Flexiworkers need not be unskilled in the technical sense. Thus the spread of teleworking (telecomputing, or remote work) often involves workers with computational skills. But they are likely to have extreme employment insecurity and have little or no labor process security, in that they are isolated from the work process, liable to be ignored in promotions, easily dismissed and unlikely to identify with unions in companies. Apparently, telecomputing has been a mechanism for geographical decentralization of work forces and even for extending the international division of labor. Some firms have set up regional centers in which teleworkers can work for part of the time. The New York Life Insurance Company, having had difficulty in retaining trained staff in its US offices, set up an office in Ireland, where it sends insurance claim forms to be processed and telephoned back to New York. Such remote working has even been used as a form of regional policy to shift jobs to high unemployment areas without the need to shift the plant or offices of firms wanting to remain in strategically placed central locations. The United Kingdom's National Economic Development Council has recently launched information technology work centers in five inner cities for precisely that purpose. In short, by such methods capital remains large and centralized; labor becomes increasingly small and decentralized.

Flexiworkers are likely to be in and out of jobs, whether full-time or part-time, but rarely in them long enough to earn entitlement to occupational welfare, social security, or even privatized insurance benefits, let alone long enough to develop the confidence to join or form unions.

Some of the characteristics of the growth of flexiworkers are too well rehearsed to bear much repetition. But one trend worth stressing is that large parts of the employment function itself may be in the process of being contracted out to intermediary, labor-only agencies - their "output" being labor. 10 This will take many forms, including "turnkey" provision of work teams of complementary groups of workers. One may confidently anticipate a lucrative profession mushrooming in the 1990s-employment contract lawyers - bargaining just like agents for football players or actors over not only salaries and benefit packages for their client workers but over such matters as employee loan arrangements between companies (a growing practice in Japanese firms), zero hours contracts, maximum/minimum working time contracts, on-call contracts, annual hours contracts, and the like.

A symbolic move in the direction of employee subcontracting was the recent abolition of Britain's national dock labor scheme, whereby dockers had obtained some semblance of income and employment security through the register of dockers, which had helped maintain minimum wages and had regulated training and skill standards. For over fifty years this symbol of decasualization had been preserved; now the prospect of labor auctions, wage undercutting, and market clearing is back. But that is only one of many such trends. Temporary employment agencies have grown for secretaries, contract cleaners, building workers, hotel kitchen staff, security services, maintenance workers, electronics company workers, and numerous others. Some of the "flexible specialist," labor-only subcontracting companies have become multinational corporations, and in some cases, the agencies have become monopolist-monopsonists, which gives them strong rent-acquisition possibilities. Already there is an International Confederation of Temporary Work Firms, which recently reported that the number of workers in the 
European Community on temporary contracts had been growing by between 15 and 20 percent a year in the 1980s, a rate expected to rise with the EC's single market after 1992. Apparently, growth had been greatest in the Netherlands, France, and the Federal Republic of Germany.

One can paint these ongoing developments as either benign or malign. The libertarian would probably contend that competition will force the agencies to offer workers incentives to stay with their agency, and there may indeed be some stabilization of employment relationships between such workers and their agencies, who will decide on their allocation to firm $x$ or $y$, with pensions, sick pay, paid leave, and the like. But there is likely to be a worrying absence of job security, in that workers will be shifted around at the will of intermediaries and the firms to whom they are contracted. This is subordinated flexibility, which can only be a threat to occupation by virtue of the incessant insecurity and casualization at the point of production. There should also be concern about the skills that such a trend emphasizes and deemphasizes. Skills that will be fostered include mobility, those underdeveloped will include understanding of production processes. This is not flexible specialization but specialized flexibility.

There has already been a proliferation of contractual forms of employment relation, and it is the associated employment insecurity that most easily identifies flexiworkers. There are contracts that cover specific categories of worker and there are contracts that are shaped by the production or management process. Broadly speaking, one might envisage the former as having rather more to do with labor force stratification and the latter with job segmentation. In recent ILO enterprise-level labor flexibility surveys we have been probing how to disaggregate labor status categories. The experience has once again highlighted the inadequacy of dualistic vocabulary. The term, for instance, covers a wide spectrum of usefully distinctive contractual relations. Here is not the place to go into the distinctions, or their implications, but just listing the main forms of employment contract indicates the fragmention process:

1 casual, without oral or written contract, typically day-work;

2 temporary, fixed-term, oral agreement, non-retention — either for a) stop-gap work, or

b) job work;

3 temporary, fixed-term, oral, on a continuing work basis - either for a) or b);

4 temporary, fixed-term, written contract, as for $2 \mathrm{a}$ or $2 \mathrm{~b}$;

5 temporary, age-limited, e.g. for youths aged 16-19 or for preretirement;

6 apprenticeship contracts, with or without assurance of subsequent employment;

7 trainee, probationary, specified or unspecified duration;

8 adaptation contracts, for post-training practical purposes;

9 temporary contracts for first-time job seekers, as in Germany;

10 job-sharing contracts;

11 employment-orientation contracts, particularly for youths;

12 solidarity contracts, involving shared cuts in wages and worktime in downturns;

13 variable time contracts, where the length of the working day or week is adjusted to

meet the firm's requirements;

14 part-time contracts, also involving features of other forms of contract;

15 regular, full-time contracts. 
This list is scarcely exhaustive, and excludes forms of dependent "self-employment," many of which reflect a comtractual relation with a specific company. Flexiworkers fit into many of the first fourteen categories, and while most of those contractual forms have always existed, it is their relative growth that is striking. The scope for employment insecurity and income insecurity in this form of "contractual fragmentation" is enormous, even though the diversity provides potential flexibility for employers and workers that might be advantageous for either or both. The threat to labor process security, or solidarity, must be considerable, for such workers typically cannot relate to their fellow workers, having no common social space into which to bond cohesively, while the regular, full-time workers are encouraged to feel apart because the employment insecurity is borne by this relatively peripheral category. But perhaps the principal characteristic of flexiworkers is that they commonly lack entitlement to both enterprise/ occupational welfare and national insurance-based state welfare. Some groups may have access to some benefits, some to others. But the dominant picture is one of exclusion and inadequacy of entitlement. Ironically, of course, they have a greater need for such benefits because they lack all six forms of labor security. This means that they are always threatened by the fear of floating into the seventh stratum.

This fragment, which also mushroomed in the 1980s, has attracted various epithets, the most controversial being "underclass," a term treated as an ideological football by the likes of Charles Murray and Lawrence Mead. But liberals have also sentimentalized its growth, often failing to criticize the productive, technological, and labor structure that generates it.11 Anyhow, one might best describe it as the detached stratum, since the defining characteristic is a detachment from regular economic activity, often involving long-term or chronic recurrent unemployment, and an equally chronic need for state transfers from outside national insurance schemes. It is from this group that the state can draw lowly paid labor to help undermine workers in other strata, and its existence must act as the biggest source of fear for those unwilling to become subordinately flexible.

The "Fordist system" may have broken down, but if so it has done so not just because mass production based on regular wage employment has shrunk but because the regulatory framework has become dysfunctional, given that more and more of the population of advanced capitalist countries have become detached from productive society, that is, detached as workers. Consumer capitalism depends on workers consuming mass-produced products, but increasingly people's identities are tied only to consumption, not to production. This applies to most of the labor fragments, most of which are not easily organizable because productively they have no collective identity. It has almost reached the stage when one cannot envisage collective class action any more, only sectional action, on for instance ethnic, age, or gender issues.

The labor regulatory framework built up in the era of welfare capitalism is also becoming dysfunctional, because more of the population are detached from productive society. They may be completely detached, as in the case of the long-term unemployed and many of those in "labor market schemes." Or they may be behaviorally detached, as with most flexiworkers, who have little continuity of employment and thus little access to nonwage components of working-class income, such as earnings-related benefits that were built up as incentives to continuity of employment, as in the Federal Republic of Germany. Historically, the social insurance welfare system has had a regulatory function, 
with earnings-related mechanisms expected to increase productivity, through incentive and worker commitment effects, and the firms' return to investment in training. But if the labor process is not generating the sort of employment for which such regulations can function to raise efficiency, then one can anticipate attempts to revise the system to secure a more effective regulatory framework. This is one reason for the drift towards workfare, which we might define as the payment of benefits conditional on some predetermined work-related activity, which includes "training" and work habituation courses. Does subordinated flexibility lead anywhere other than to workfare?

Labor process fragmentation erodes the integrative functionality of both Beveridge and Bismarckian social security systems. They were conceived primarily to foster productivity and ensure income security; they have become means of weakening labor process security and of undermining labor market security, simply because the former relies on common interests and the latter depends crucially on workers having effective freedom in the labor market. The more complex the system, the more the regulatory objectives will be uppermost. Moreover, as argued elsewhere, with labor flexibility and fragmentation, the contributory base tends to shrink and benefit entitlement tends to narrow and grow weaker. Many of those advocating more flexibility also contend that welfare encourages and strengthens behavioral dependency, and in that spirit governments have shifted towards "targeting," means tests, tighter conditionality, tighter behavioral monitoring, and the promotion of "welfare pluralism." In many countries one sees a strong underlying trend towards some variant of workfare, which is scripted to play a major role in the libertarian cinema of the 1990s.

A final labor process trend closely associated with the growth of subordinated flexibility, and to the trends to targeted or pluralist welfare and workfare, is the changing role of "training." This stems from the perceived need to raise productivity. The basic supply-side view is that wage differentials should widen and be more individualized, the orthodox ideology being that the rich need more to give them the incentive to work, while the pool need less to make them work. But along with more flexible payment systems, ostensibly designed to promote productivity, has been a trend that deserves more critical attention than it has received, the growth of what might be called "trainingitis," which derives from the erosion of skill in the traditional senses of that term. The more occupations are split into jobs, the more labor statuses are flexible, and the larger the sixth and seventh labor force strata grow, the greater the need for job training and labor market training. In many European countries the role of the state in this has grown enormously, and the script is that a larger proportion of the population will have work "careers" consisting of flexible combinations of short-term jobs preceded and succeeded by training and retraining, a pattern potentially leading to a whirlwind of jobs interspersed with training. Some observers have talked about an "active society" for the 1990s, based on benign presentations of this twilight zone of intermittent training and productive activity. But individualized workers obliged to shift from pillar to post in a fashion determined for them by the state, or by any other regulatory body, are scarcely likely to lead the way to the acta vita idealized so memorably by Hannah Arendt.

In sum, if the libertarian, supply-side path to flexibility persists, the following scenario seems the most likely:

1 a contractualization of the labor process, with proindividualistic regulations 
constraining collective action;

2 welfare pluralism, with the state as fall-back "safety net" provider, with privatized benefits for the upper strata and with voluntary private services left to fill the gaps left by an incomplete insurance system (a model presented as "the caring society" in the Netherlands) (de Neubourg 1990);

3 privatization of social policy as well as of economic spheres;

4 workfare replacing means-tested and universal transfer payments for those deemed to be "employable";

5 more policing of welfare "scroungers";

6 a steadily growing police presence in civil society to control the losers in an aggressively competitive economic environment;

7 a neo-corporatist state based on an overt employer-government alliance to replace tripartism, with trade unions shrinking and shackled by legislation and their own fragility in the context of flexible labor markets and fragmented productive systems.

Whether or not these are exaggerated as stated, they are sufficiently present as trends to suggest that a search for alternative paths would be reasonable.

\section{TOWARDS COOPERATIVE FLEXIBILITY}

There is a nucleus of another route to labor process flexibility, which builds on the corporatist traditions kept alive in the Nordic region, but which combats a critical limitation of the Nordic models. An essential element of any viable alternative must be the avoidance of labor fragmentation and income insecurity. Yet the danger is that critics of subordinated flexibility and supply side trends of the 1980s will continue to give primacy to labor market and employment security. Neither of these is really a meta right, though both should be seen as instrumental to the promotion of other labor rights. Treating them otherwise ultimately undermines their political legitimacy.

The error of the old social democratic "laborist" route to the Good Society lies in a faulty syllogism: there is a right to work; all rights imply duties; therefore, there is a duty to labor. One could give countless examples of unfortunate deductions from this line of reasoning. Thus, to give just one minor instance, it was characteristic that a recent international meeting of trade unionists concluded that the answer to the inadequacy of social security provision associated with the growth of more flexible forms of employment was more full-time jobs (OECD 1989:7). But one may guess that full-time wage employment is neither desired by the majority nor desirable on efficiency or equity grounds. As noted earlier, if full-time wage employment is treated as a meta right, then one must favor market clearing wages, whatever they may be, and a compromise on various other forms of labor security, notably labor process and work security.

Full employment is always possible. They managed it fairly well in slave societies, which may not be the best recommendation. However, it is not a means of removing labor fragmentation, nor is it any more a reliable means of reversing the inequalities and erosion of labor process security. Recognition of that seems essential if policy reform is to take advantage of current realities without drifting into some atavistic cul de sac, such as the mass creation of "public-sector jobs." In that context, in some places, often in a rather 
disjointed manner, mechanisms for promoting active rather than subordinated flexibility have been taking shape. We may be in the midst of an era of social experimentation, in the course of which partial reforms may be pieced together to create the basis for a much more flexible lifestyle by the end of the twentieth century. The vision must surely be a social structure in which labor process security and income security are guarded and enhanced as meta rights.

Such reforms are taking a number of complementary directions, and one feels that they would fuse much more successfully and sooner if we could articulate the type of social and labor structure that we would like to create. Here it might be useful merely to outline the types of reform that may be shaping an alternative path to labor flexibility.

First and foremost, unless organizations can be revived to represent the collective voice of the vulnerable segments of society, notably those in the sixth and seventh strata, the necessary impetus to sustainable nonsubordinated flexibility will not emerge or will be dissipated. That is why we need to be concerned with alternative regroupings of unions, and in particular the possibility of communal unions evolving in place of industrial or craft unions. Recently, a variant of this has also been called "associational unionism," since it associates individualized workers who could benefit from collective representation. If workers are "postcapitalist labor" in the sense of not being in stable proletarianized relationships, they will be uncommitted to industrial unionism, just as flexiworkers can scarcely be expected to be committed to craft unionism, besides being hard to organize or to retain. But communal unionism will also not flourish if the organization merely represents an agency for job placements, advisory services, personal loans, and a source of social security for their members, even though all those functions are desirable. If that is all unions become, the state or private commercial firms will always try to turn them into individualistic entities. Only if they are constantly concerned with the primary problem of the era, redistribution, will they develop a pivotal role. There are signs that moves to redefine communal solidarity are growing in significance, and that the promotion of economic democracy, as well as industrial and political democracy, will be high on the agenda in the 1990s. Without economic democracy, one can see no alternative to the type of subordinated flexibility sketched earlier.

More advanced in practical terms is discussion and application of experimental policies to promote flexible lifestyles that build on the fragmenting tendencies in the labor process. Many of those are double-edged, in that they could be either converted into instruments of intensifying subordinated flexibility or integrated with other policies that together promote a more active, egalitarian flexibility.

If there are more part-time employment slots, and if there is a perceived need to have quicker responses to economic restructuring - perhaps as a result of more rapid and pervasive technological innovation - then it makes little sense to hope to buck the trend. It makes much more sense to facilitate flexible work patterns on terms desired by workers. That is one reason for foreseeing an era of social experimentation. Haltingly, one sees the nucleus of what could be called a social dividend route to flexibility, called that because ultimately it is based on redistributing the economic surplus through ways other than wage income and welfare (Standing 1989). This route would also give precedence to the right to work over the right to employment, bearing in mind that a right to do something can only exist if there is a matching right not to do it. 
One could argue that a social dividend approach is crystalizing in the various experimental policies and institutional developments taking place in various parts of Europe. One thinks of sabbatical year and "time bank" debates in Sweden and Finland, solidarity contracts in Belgium, partial retirement schemes, career break and parental leave arrangements, the revenu minimum d'insertion in France, wage earner funds, renewed interest in profit sharing, the renewed growth of cooperatives in Italy and elsewhere (including the former Soviet Union, in a big way), industrial districts in the Federal Republic of Germany and in other countries, and so on. Experimentation is the general principle of the moment. Thus old ideas about time banks have been repackaged as less radical reforms. And, for instance, in Finland a government committee was set up to consider how sabbatical years could be phased into existence, with the state arranging for all workers to have the right to periodic breaks from their main labor force activity (Lilja, Santamäki-Vuori, Standing 1990). Partial retirement schemes and the removal of arbitrary retirement age notions are widely regarded as cautious steps in the general direction of lifetime flexibility, especially in the context of the ageing of European societies, though such schemes can be and have been easily turned into sources of inequity and discrimination unless developed in the appropriate institutional context.

One also notices more constructive discussion of unconditional income transfers, or citizenship income grants. That would decouple labor market status and behavior from income security and facilitate flexible combinations of productive and reproductive activities, helping in the process to legalize the shadow economy and encourage the growth of the "informal" economy. As long as governments lack the courage to promote the genuine right to income security, that is, unconditional, universal, and individual, the "flexible specialization" potential will be restricted, and the potential pursuit of occupation stultified. Basic security from deprivation as a citizenship right will be a necessary condition. It is not the only one, for to create an environment of cooperative flexibility will require labour process security, to prevent the vulnerable from being systematically marginalized, and thus being a threat to the working community, and to combat the coercive potential of contract law replacing collective regulation. There must be regulation to provide the basic safeguards against the structural inequalities that market mechanisms are bound to produce and intensify. That is why work security and payment system security (including minimum wage protection) will remain essential components of any path to an active flexibility society. But, ultimately, the institutional structure that promotes labor process security will be far more significant for that than any number of regulations. New forms of union, new forms of collective agency and new meanings of solidarity will need to emerge.

\section{CONCLUDING POINTS}

Since work was begun on this chapter, political events in Eastern Europe and the Soviet Union have given these deliberations a new poignancy. A bogeyman has been removed, exorcised, and after a year or two debates about the direction of social policy may become decidedly more progressive as a consequence. The market-oriented orthodoxy is promoting subordinated flexibility everywhere, but in the wings is an emerging paradigm 
based on cooperative flexibility. For that to succeed it is essential that we focus on forms of recovering and extending labor process security. Trade unions are almost anachronistic in societies where trades or crafts are made ephemeral. Industrial unions are enfeebled by the multinational, multiindustrial nature of capitalist conglomerates. There must be moves downstream so that unions represent the aspirations and needs of all the groups in our fifth, sixth and seventh labor strata. The only way for such organizations to emerge as class-based organizations is to diminish the fear factor, and the only way to do that is to shift the social security system in the direction of decoupling the labor market from the provision of income security. If one sees the existing welfare system as a regulatory device, then critics of the trend to subordinated flexibility should want to revise it radically. That surely is one of the two keys to creative, cooperative flexibility, the other being economic democracy in some form.

At present, the fragmentation of society is such that political democracy and the prevailing welfare institutions are far more likely to cement the divides than to reduce the marginalization of flexiworkers and detached groups. A majority could almost always be mobilized politically to reduce the rights and the security of the vulnerable minorities. Enabling large numbers to make the transition from the bottom three strata into the others, let alone disintegrating the artificial fragmentation of the labor process, is scarcely feasible unless the institutional basis of income provision and work organization is revised.

In sum, an alternative path to flexibility will have to be based on the promotion of the meta rights of labor process and income security, and will have to evolve through institutional mechanisms geared to create three forms of democracy-political democracy, industrial democracy (i.e. through codetermination to ensure work security, protective regulations, etc.), and economic democracy (i.e. through institutional mechanisms to redistribute economic surplus equitably, involving the collectivization of profits and citizenship income dividends). This would effectively reverse the traditional social democratic and socialist agenda, since rather than nationalize the means of production, it would privatize the management and ownership functions while socializing the surplus. The form of this alternative framework is still very far from clear, but the contours are beginning to take shape.

\section{ACKNOWLEDGMENTS}

Views expressed in this chapter are not necessarily those of the ILO. Thanks are due to Kate McFate for useful discussions. 